\title{
Interfacial Electron Transfer Dynamics of Photosensitized Zinc Oxide Nanoclusters
}

Kei Murakoshia, Shozo Yanagida ${ }^{a}$, Malcolm Capelb, and Edward W. Castner, Jr.c

\author{
aMaterial and Life Science, Graduate School of Engineering, \\ Osaka University \\ bBiology Department, Brookhaven National Laboratory \\ cChemistry Department, Brookhaven National Laboratory
}

\begin{abstract}
We have prepared and characterized photosensitized zinc oxide $(\mathrm{ZnO})$ nanoclusters, dispersed in methanol, using carboxylated coumarin dyes for surface adsorption. Femtosecond time-resolved emission spectroscopy allows us to measure the photo-induced charge carrier injection rate constant from the adsorbed photosensitizer to the $n$-type semiconductor nanocluster. These results are compared with other photosensitized semiconductors.
\end{abstract}

\section{Introduction}

Photosensitized nanoclusters of wide bandgap n-type semiconductors are promising systems for efficient solar energy conversion. ${ }^{1}$ A photosensitizing dye adsorbed onto the surface of the semiconductor can inject an electron into the semiconductor, which could possibly be used directly in a solar photovoltaic device or stored in a battery. A system design goal is to select a dye/semiconductor pair for which the ground electronic state of the dye will lie in the bandgap between valence and conduction bands of the semiconductor, while the excited state of this dye will have an energy slightly higher than the sum of the conduction band edge and interfacial electron transfer reorganization energies. Several dyes have been used as photosensitizers, including organic laser dyes, porphyrin derivatives, and inorganic complexes of ruthenium, osmium, and iron. A number of semiconductor materials have been studied for this application, including $\mathrm{TiO}_{2}, \mathrm{SnO}_{2}, \mathrm{SnS}_{2}$, and $\mathrm{ZnO}$. For an overview of these studies of dye-sensitized electron-transfer at the electrode interface, we refer to the chapter by Willig. ${ }^{2}$

Zinc oxide electrodes photosensitized by a number of dyes were first reported by Gerischer and Tributsch. ${ }^{3,4}$ Photosensitizers included riboflavin, eosin, rose bengal, rhodamine $B$, and cyanine dyes. Higher efficiency was achieved in similar systems by Tsubomura, et al. ${ }^{5,6}$ using sintered porous disks of $\mathrm{ZnO}$. This preparation was used in order to achieve a sufficiently high surface coverage of 
adsorbed dye on the $\mathrm{ZnO}$ electrode. Similar results using Rhodamine $\mathrm{B}$ and $\mathrm{Ru}^{\mathrm{II}}$ polypyridyl dye sensitized sintered-porous $\mathrm{ZnO}$ were also reported by Alonso, et al. ${ }^{7}$ $\mathrm{TiO}_{2}$ has also been extensively used as a photosensitizer, with the first report for single-crystal rutile photosensitized by $\mathrm{Ru}(\mathrm{bpy})_{3}{ }^{2+}$ and its derivatives given by Clark and Sutin. ${ }^{8}$ A number of researchers have prepared and characterized nanocrystalline $\mathrm{ZnO}$, including Spanhel and Anderson, ${ }^{9}$ Bahnemann, ${ }^{10}$ and Cavaleri, et al. ${ }^{11}$ The results mentioned here provide the foundation for the present study.

A number of different types of photosensitizers for metal-oxide semiconductors have been studied, including both organic and inorganic complex chromophores. For strong binding between the photosensitizer and the metal-oxide semiconductor surface, a carboxylate, phosphonate, or sulfate group on the photosensitizer molecule is needed ${ }^{12-14}$. In the experiments presented here, we use 7-aminocoumarin chromophores that have a carboxylate substituent at the 3position. The carboxylate, perhaps in concert with the 2-position carbonyl oxygen, binds to one or more metal-cation surface sites. The three coumarins used in this study are shown in Scheme I.

Scheme I:

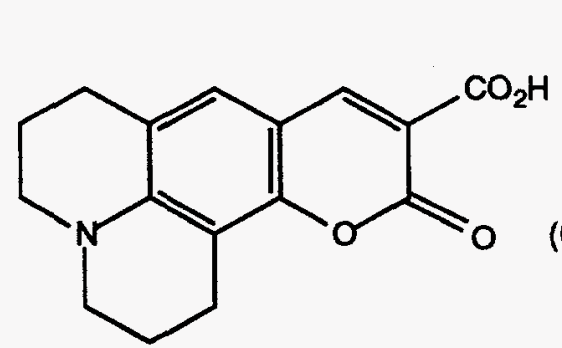

Coumarin 343

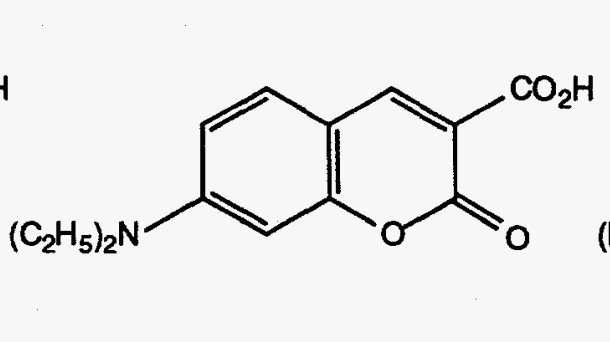

Coumarin D-1421<smiles>CN(C)c1ccc2c(CO)cc(=O)oc2c1</smiles>

Coumarin D-126

Excited-states of coumarin molecules can be rapidly oxidized or reduced by quenchers of the appropriate electrochemical potential. Typical emission lifetimes of 3 to $5 \mathrm{~ns}$ are shortened to sub-picosecond levels in either case for homogeneous solution-phase bimolecular photo-induced electron-transfer. ${ }^{15,16}$ Interfacial electron-transfer dynamics for coumarins adsorbed onto semiconductors can also be very rapid. ${ }^{17,18}$ The ruthenium dye system used by Grätzel and co-workers ${ }^{1,19}$ has recently been shown to undergo very rapid interfacial electron-transfer when adsorbed onto nanocrystalline $\mathrm{TiO}_{2}{ }^{20}$

Use of colloidal preparations of the semiconductor nanoclusters provides several advantages, including very high surface area for binding of photosensitizer, and straightforward solution-phase material preparation. The promising efficiency of such photoelectrochemical systems depends on very rapid forward electrontransfer from dye to semiconductor, rapid charge separation, slow back electrontransfer, and a large absorption cross-section for the dye at appropriate visible wavelengths. A focus of our present work has been to characterize the very rapid forward electron-transfer rate. In aqueous photosensitized $\mathrm{TiO}_{2}$ systems, we have measured forward photo-induced electron-transfer rate constants greater than $2.5 \mathrm{x}$ $10^{13} \mathrm{~s}^{-1.18}$ By comparison, methanol dispersions of photosensitized $\mathrm{TiO}_{2}$ and $\mathrm{ZnO}$ 


\section{DISCLAIMER}

This report was prepared as an account of work sponsored by an agency of the United States Government. Neither the United States Government nor any agency thereof, nor any of their employees, make any warranty, express or implied, or assumes any legal liability or responsibility for the accuracy, completeness, or usefulness of any information, apparatus, product, or process disclosed, or represents that its use would not infringe privately owned rights. Reference herein to any specific commercial product, process, or service by trade name, trademark, manufacturer, or otherwise does not necessarily constitute or imply its endorsement, recommendation, or favoring by the United States Government or any agency thereor. The views and opinions of authors expressed herein do not necessarily state or reflect those of the United States Government or any agency thereof. 


\section{DISCLAMMER}

Portions of this document may be illegible in electronic image products. Images are produced from the best available original document. 
both show reaction rates constants that are substantially slower. For the methanol dispersions, the forward electron-transfer rate constants can exceed $10^{11} \mathrm{~s}^{-1}$.

The general scheme for photosensitization of semiconductor nanoclusters is illustrated in Figure 1. On the left are closely spaced but discrete energy levels. These represent both the valence and conduction bands of the semiconductor nanocluster. The levels will be described neither by a continuum, as for a single crystal semiconductor, nor by the distinct and broadly spaced exciton levels (quantum confined) seen in other smaller diameter nanocrystalline materials such as CdS and CdSe. Other energy levels will lie in the bandgap region between valence and conduction band edges, including surface states and shallow and deep traps. To the right, the energy levels of the photosensitizing dye are indicated. It is desirable that the ground state labeled $S_{0,0}$ should lie between the valence and conduction band edges. The optical transition energy to an excited state, $\mathrm{E}\left(\mathbf{S}_{1, \mathrm{v}}-\mathbf{S}_{0,0}\right)$ should be substantially less than the bandgap, to avoid optical excitation of the semiconductor. There will be some competition between direct electron transfer from the dye excited state to the semiconductor and other radiative and non-radiative excited state relaxation pathways. Alternative relaxation channels include very rapid intramolecular vibrational relaxation and inertial solvent relaxation. A more accurate description would have the electrontransfer event taking place from any of the dye excited vibrational levels, at any point along the solvent relaxation coordinate, into several conduction band levels. If the interfacial electron transfer is to be adiabatic, then the vibrationally relaxed dye excited state $S_{1,0}$ must have an energy difference relative to the conduction band edge greater than the reorganization energy for the interfacial electron-transfer reaction, or 0.1 to $0.5 \mathrm{eV}$. More detailed discussion of these and other important details can be found in the review articles. ${ }^{1,2}$

Surface characterization of the binding of photosensitizers to metal-oxide surfaces is possible for single crystal sites in ultra-high vacuum (UHV). ${ }^{21}$ However, it is more difficult to determine the binding geometry for the photosensitized nanocluster dispersed in methanol. Evidence from surface science studies of single crystals in UHV reveals that metal oxides, such as $\mathrm{ZnO}$, adsorb an alkoxide coating via proton dissociation from alcohols. Previous studies on $\mathrm{SnS}_{2}$ surfaces have found that the nature of the photosensitizer adsorption changes with increasing surface coverage.22 In our own work, a parallel study of the same coumarins used to photosensitize $\mathrm{TiO}_{2}$ showed substantially different steady-state and time-resolved spectra as a function of surface coverage. ${ }^{18}$ Also apparent for $\mathrm{ZnO}$ is that the $\mathrm{Zn}^{2+}$ surface cationic site will bind carboxylic acids as carboxylates under UHV conditions. ${ }^{21}$ Molecular modeling studies indicate that there exist several distinct binding geometries for the carboxylated dye on the semiconductor surface. Though direct detection of the nature of surface binding was unavailable from IR spectral data for the sols of photosensitized nanoclusters, dried films of Ru(II) polypyridylcarboxylate dyes adsorbed on $\mathrm{TiO}_{2}$ have previously been shown to have bind with both ester-like and chelate carboxylate geometries relative to the $\mathrm{Ti}^{4+}$ binding site. ${ }^{23}$

Despite the disclaimers above, we propose examples of four possible binding configurations that were observed to be feasible during molecular modeling. To properly model the surface binding, one would have to build a complex model incorporating at least two atomic layers at the $\mathrm{ZnO}$ nanocluster surface; 
calculations of the electronic structure of the ground, excited, and radical-cation energy levels of the photosensitizer and the band structure of the semiconductor (including quantum confinement); the effects of probable methoxide adsorption on nearby binding sites; and a realistic model for the solvent. Because such a model is presently an intractable computational problem, we instead examined crude models for the binding of coumarins D-1421 or 343 on $\mathrm{ZnO}$, and deduced the proposed interactions shown in Figure 2. Though aromatic dye chromophores will bind directly (but weakly) to the semiconductor surfaces, the strength of the binding interaction is greatly increased if a specific chemical interaction between functional groups on the photosensitizer and the semiconductor nanocluster surface is used. Carboxylate and phosphonate groups have been used previously to tether dyes to $\mathrm{TiO}_{2}$ and $\mathrm{ZnO}$ surfaces. ${ }^{14,19}$ The coumarin dyes in Scheme I can interact with the $\mathrm{Zn}^{2+}$ cation sites on the surface in several ways. Besides a mono-ether type of linkage, more likely candidates for surface binding structures include a bridged or chelated structure for the carboxylate group, or a bridged or chelated geometry from the carbonyl at the coumarin ring 2-position and one of the 3-carboxylate oxygens. It is known that the distance between metal atoms on the $\mathrm{Zn}$-atom surface $(0001$ face) of $\mathrm{ZnO}$ is $3.25 \AA .24$ The distance between oxygen atoms on a carboxylate group of one of these coumarins is about $2.45 \AA$, whereas the distance between the 2position carbonyl oxygen and a carboxylate oxygen on coumarin 343 or D-1421 is about 2.6 $\AA$. Given these distances, it seems likely that the chelate rather than the bridge structures shown in Figure 2 are more likely. If one of the chelate structures is in fact the most stable, this would explain why the third coumarin, D-126, does not seem to bind to the $\mathrm{ZnO}$ surface: $\mathrm{D}-126$ cannot form the either of the salicylate geometries.

\section{Experimental}

Materials. Zinc acetate dihydrate $\left(\mathrm{Zn}\left(\mathrm{CH}_{3} \mathrm{COO}\right)_{2} \cdot 2 \mathrm{H}_{2} \mathrm{O}, 99.9 \%\right.$, Wako Pure Chemicals), lithium hydroxide monohydrate ( $\mathrm{LiOH} \cdot \mathrm{H}_{2} \mathrm{O}$, reagent grade, Wako Pure Chemicals), hydrochloric acid ( $\mathrm{HCl}, 37 \mathrm{wt}$. \%, reagent grade, Aldrich) were used as received. The solvents methanol, acetonitrile, and 2-propanol (spectral grade, Aldrich) were used without further purification. Ethanol for the preparation of zinc oxide ( $\mathrm{ZnO}$ ) nanocrystallites was purified by fractional distillation just before use.

The dyes coumarin 343 (laser grade, Acros Organics), 7-diethylaminocoumarin-3-carboxylic acid (D-1421, Molecular Probes Inc.), and 7-dimethylaminocoumarin-4-carboxylic acid (D-126, Molecular Probes Inc.) were used as received. $\mathrm{ZnO}$ nanocrystallites were prepared under a dry nitrogen atmosphere following the method of Spanhel and Anderson. ${ }^{9}$ An ethanol solution $(500 \mathrm{ml})$ of $\mathrm{Zn}\left(\mathrm{CH}_{3} \mathrm{COO}\right)_{2} \cdot 2 \mathrm{H}_{2} \mathrm{O}(0.1 \mathrm{M})$ was placed into a 1-L round-bottom flask fitted with a $\mathrm{CaCl}_{2}$ moisture trap. The solution was boiled with stirring at $80^{\circ} \mathrm{C}$ for $3 \mathrm{~h}$. The condensate was collected continuously. After this procedure, $200 \mathrm{ml}$ of reaction mixture and $300 \mathrm{ml}$ of condensate were obtained. The suspended reaction solution $(200 \mathrm{ml}$ ) was diluted to yield $500 \mathrm{ml}$ of ethanol solution containing $0.1 \mathrm{M} \mathrm{Zn}$. Then, $0.07 \mathrm{~mol}$ of $\mathrm{LiOH} \cdot \mathrm{H}_{2} \mathrm{O}$ was added to the ethanol solution in an ultrasonic bath at 30 ${ }^{\circ} \mathrm{C}$, resulting in transparent ethanol solution of $\mathrm{ZnO}$ nanocrystallites. The colloidal solution of $\mathrm{ZnO}$ nanocrystallites was evaporated at $50^{\circ} \mathrm{C}$ and further dried in vacuo (ca. $1 \mathrm{~mm} \mathrm{Hg}$ ) at room temperature for $12 \mathrm{~h}$, yielding a white powder of $\mathrm{ZnO}$ 
nanocrystallites. The resulting white powder of $\mathrm{ZnO}$ nanocrystallites was welldispersible in dry ethanol and was stable more than 3 days. These results coincide with the literature report of Spanhel and Anderson. ${ }^{9}$ Concentrations of $\mathrm{ZnO}$ ethanol dispersions were determined by absorption at $340 \mathrm{~nm}$.

Apparatus. Absorption spectra were measured at room temperature on a Hitachi U-3300 spectrophotometer or a Hewlett Packard model 8452A photodiode array spectrophotometer. Emission spectra were measured at room temperature on a Hitachi Model 850 fluorescence spectrophotometer or a custom built multichannel spectrophotometer. The excitation source for this latter emission spectrometer is from a $10 \mathrm{~nm}$ bandpass monochromator-filtered Xelamp source, with front-surface fluorescence collection. In this instrument the emission was focused into a 0.5 meter focal length spectrometer, with detection by a $1152 \times 256$ element liquid-nitrogen/thermoelectric cooled CCD detector. Backgroundsubtracted spectra were measured for 5 to 300 second accumulation times. Highresolution transmission electron microscopy (TEM) images and electron diffraction patterns were obtained on a Hitachi H-9000 instrument, operating at $300 \mathrm{kV}$. Small-angle x-ray scattering (SAXS) measurements were carried out at the National Synchrotron Light Source, beamline X12B. ${ }^{25}$

Electrochemical measurements were carried out using a Bioanalytical Systems potentiostat (BAS 100B). Reduction potentials of coumarin dyes were measured by cyclic voltammetry in acetonitrile solutions containing $0.2 \mathrm{M}$ of tetraethylammonium perchlorate using a glassy carbon working electrode, measured versus $\mathrm{SCE}$.

Ultrafast Spectroscopy. The fluorescence upconversion instrument will be described in a future publication. ${ }^{26}$ The design of the instrument is nearly identical to that constructed by the Maroncelli group, described recently in detail. ${ }^{27}$ This type of upconversion spectrometer with all-reflective fluorescence optics was described previously by Rosenthal, et al. ${ }^{28}$ Important details of the Brookhaven instrument are described below.

For the upconversion experiment, 10 to $80 \mathrm{~mW}$ average power $(82 \mathrm{MHz}$ pulse repetition frequency) of second-harmonic laser light (from a Spectra-Physics Tsunami fs Ti:sapphire laser) was used to excite the sample at wavelengths in the $390-425 \mathrm{~nm}$ range. A Type I phase-matched nonlinear optical crystal $(0.3 \mathrm{~mm} \mathrm{LBO}$, lithium triborate, or $0.4 \mathrm{~mm} \mathrm{BBO}$, meta barium borate) was used for secondharmonic generation. Sample solutions were continuously flowed through a $1 \mathrm{~mm}$ path fused quartz flow cell. The emission was gated with near-infrared pulses at the fundamental wavelength $(780-850) \mathrm{nm}$, by sum-frequency mixing fluorescence and laser fundamental in an angle-tuned, $0.4 \mathrm{~mm}$ path $\mathrm{BBO}$ nonlinear crystal. The upconverted (or sum-frequency) light was detected by a photon counter after passing through a $150 \mathrm{~mm}$ focal length monochromator ( $5 \mathrm{~nm}$ bandpass), tuned to the ultraviolet sum-frequency wavelength corresponding to emission at 425-600 nm. The sample was excited with 'magic-angle' polarization (linearly polarized with angle $54.7^{\circ}$ from vertical) to eliminate polarization anisotropy contributions to the emission dynamics. The fluorescence was polarization gated by the BBO crystal to detect vertically polarized emission. Accumulation times of 1 to 20 seconds/point were used, with one to four emission transient scans summed to provide the final raw data set. After each scan, the scanning delay stage was reset to the peak signal 
position, and the signal intensity was checked to verify that the sample had not degraded, and that the laser pulse intensity had not changed.

The temporal instrument response function was measured by tuning the BBO sum-frequency crystal to phase-match the third-harmonic of second-harmonic excitation and the fundamental gating beams at $260-284 \mathrm{~nm}$. The measured thirdharmonic cross-correlation was in the range 130-160 fs (fwhm), and fit well to a Gaussian function, implying a pulse resolution of 90-115 fs. Nonlinear leastsquares fitting was done with a program using the Levenberg-Marquardt algorithm, where a model function was iteratively convoluted and compared with the raw data. Best fits to the data were obtained using sums of exponential functions, where it is necessary to consider both rising and decaying components to find the best fit.

Emission lifetimes of the unbound photosensitizing dyes in solution were measured using a time-correlated single-photon-counting (TCSPC) instrument. This instrument is similar to a number of others, ${ }^{29}$ except that femtosecond pulses from the Spectra-Physics Tsunami laser at $82 \mathrm{MHz}$ were pulse selected at $4.1 \mathrm{MHz}$ using an acousto-optic modulator instead of using a cavity-dumped picosecond dye laser. The 4.1 MHz pulse train was frequency doubled using a $1 \mathrm{~mm}$ Type I BBO crystal, providing $<1 \mathrm{~mW}$ of average power. The sample was contained in a $1 \mathrm{~cm}$ path fused silica cuvette, held in an Acton Research Corp. sample chamber attached to their SP-150 spectrometer equipped with a 1200 line $/ \mathrm{mm}$ grating, for $5 \mathrm{~nm}$ bandpass. A Hamamatsu R3809-50U micro-channel plate photomultiplier (MCPPMT) detected the emission with maximum count rates $<40 \mathrm{kHz}$. A Philips electronics 6954-50X pre-amplifier was used, with a $3 \mathrm{~dB} / 18 \mathrm{GHz} 50 \Omega \mathrm{SMA}$ attenuator placed between the MCP-PMT and the pre-amp. A dichroic beamsplitter was used to remove the fundamental laser beam, which was then routed through a fiber-optic to a Newport D-100 ultrafast photodiode ( $<100 \mathrm{ps}$ fwhm). EG\&G/Ortec 9307 PicoTiming discriminators were used in both emission and laser pulse signal channels. Reverse counting methods were used: the signal from the MCP-PMT provided the start signal for the Oxford/Tennelec TC864 time-amplitude converter (TAC), while the D-100 photodiode signal provided the $4.1 \mathrm{MHz}$ stop signal. The histogram of single-photon arrival times was generated by the Oxford PCAMultiport multichannel analyzer. Using non-dairy coffee whitener, the measured instrument response is about $45 \mathrm{ps}$, fwhm. Analysis of the emission decays was carried out as for the fluorescence upconversion transients.

\section{Results and Discussion}

An atomic level characterization of the adsorbed dye on the $\mathrm{ZnO}$ nanocluster surface in methanol dispersion is not yet achievable. However, we have characterized the $\mathrm{ZnO}$ nanoclusters dispersed in methanol, before photosensitization. Steady-state absorption spectra for $\mathrm{ZnO} / \mathrm{MeOH}$ dispersions show an onset at $350 \mathrm{~nm}(3.54 \mathrm{eV}$ ), with a peak at $330 \mathrm{~nm}(3.76 \mathrm{eV})$. This value of $3.54 \mathrm{eV}$ for the $\mathrm{ZnO}$ bandgap should be compared with the bandgap of single crystal $\mathrm{ZnO}$ at $3.2 \mathrm{eV}$. These results are in good agreement with the spectral characterization of Spanhel and Anderson. ${ }^{9}$ In a study of the size dependence of electron dynamics in $\mathrm{ZnO}$ nanoclusters, Cavaleri, et al. ${ }^{11}$ used the model of Nosaka ${ }^{30}$ to estimate the particle diameter as a function of the absorption onset energy. Extrapolating from the Cavaleri, et al: ${ }^{11}$ curve for $\mathrm{ZnO}$ with a $2 \mathrm{eV}$ potential well depth, we find that a diameter of $4 \mathrm{~nm}$ is predicted. 
Our $\mathrm{ZnO}$ nanoclusters have been characterized by TEM and SAXS. TEM analysis revealed that $\mathrm{ZnO}$ consists of hexagonal $\mathrm{ZnO}$ nanocrystallites with a mean diameter of $4 \mathrm{~nm}$. The SAXS data are shown in Figure 3. The raw data are shown in the top of Figure 3, with a Guinier plot of log intensity versus scattering wavevector squared shown in the bottom. A fit to the Guinier equation ${ }^{31}$ resulted in a radius of gyration $R_{g}=16.6 \AA$. Because the particle size distribution is wide, we estimate that this radius has a distribution width greater than $15 \%$ of the mean. Converting to a particle diameter $\left(R_{\text {sphere }}=(5 / 3)^{0.5} R_{g}\right)$ we find that the SAXS analysis provides a value of $43 \AA$, in good agreement with the estimates from the Nosaka model and the absorption onset. The Bohr radius for the lowest energy exciton in $\mathrm{ZnO}$ has been estimated to be $12.5 \AA^{32}$ Thus, for $43 \AA$ diameter particles, we expect partial quantum confinement, and this is manifested by the blue-shift of the bandgap relative to bulk $\mathrm{ZnO}$, vide supra.

The x-ray analysis of the $\mathrm{ZnO}$ preparation done by Spanhel and Anderson ${ }^{9}$ showed that the resulting nanoclusters have the wurtzite structure of bulk $\mathrm{ZnO}$. Assuming the bulk density of $5.61 \mathrm{~g} \mathrm{~cm}^{-3}$ for the nanoclusters, we can deduce a number of other important parameters. Comparing the surface area of the nanocluster with that of a bulk spherical surface area, we find that the $43 \AA$ nanoclusters have $>160,000$ times more surface area. This is an obvious reason why photosensitized nanocrystalline materials offer great promise over bulk semiconductors, because the available surface area for dye binding is so many orders of magnitude larger.

For the photosensitized nanoclusters, we have estimated the apparent association constant for coumarin 343 chemisorbed on $\mathrm{ZnO}$ to be $\mathrm{K}_{\mathrm{app}}=1910 \mathrm{M}^{-1}$, obtained from the steady-state fluorescence quenching of coumarin 343 by $\mathrm{ZnO}$. This value for $\mathrm{K}_{\mathrm{app}}$ indicates strong binding of the dye to the $\mathrm{ZnO}$ surface. We can estimate the surface coverage from the relative dye concentrations and the surface area per nanocluster. Using the $43 \AA$ diameter estimated from the SAXS data, we obtain surface areas and volumes per nanocluster of $A_{s}=7.9 \times 10^{-13} \mathrm{~cm}^{-2}$ and $\mathrm{V}=6.5 \times 10^{-20} \mathrm{~cm}^{-3}$, respectively. Using the molecular weight of $\mathrm{ZnO}(81.37 \mathrm{~g}$ $\mathrm{mol}^{-1}$ ) and the bulk density, we find that for a methanol dispersion of $10^{-2} \mathrm{M}$ concentration, we have a $\mathrm{ZnO}$ volume of $1.45 \times 10^{-4} \mathrm{~cm}^{-3}$ in $1 \mathrm{~cm}^{-3}$ volume of dispersion. Dividing by the volume of a single nanocluster, we.find that there are $3.5 \times 10^{15}$ nanoclusters in $1 \mathrm{~cm}^{-3}$ of dispersion. Assuming $100 \%$ binding of the dye contained in the dispersion at $10^{-4} \mathrm{M}$ concentration, we find $6.02 \times 10^{16}$ dye molecules adsorbed onto $3.5 \times 10^{15}$ nanoclusters, for an average surface coating of 17 dyes per nanocluster. Alternatively, we can estimate the fractional surface coverage. If we assume one of the salicylate type binding geometries shown in Figure 2, we can estimate the surface area covered by a coumarin dye molecule to be 3.4 $\AA$ thick for the aromatic ring, and about $8 \AA$ across, for a subtended area per dye molecule of $2.7 \times 10^{-15} \mathrm{~cm}^{-3}$. Dividing by the surface area of one $43 \AA$ diameter $\mathrm{ZnO}$ particle, and multiplying by 17 dyes/particle, we find that the surface coverage $\theta$ for $10^{-4} \mathrm{M}$ dye/ $10^{-2} \mathrm{M} \mathrm{ZnO}$ would be $\theta=0.06$. Our dye concentrations ranged from 90 to $170 \mu \mathrm{M}$ for the optical experiments, so that we were working with surface coverages $\theta$ in the range of $5-10 \%$.

Electrochemical characterization of the three coumarin dyes showed that D126 has a substantially different electronic structure than coumarins 343 or D-1421. 
Quasi-reversible behavior was observed in the electrochemical oxidation of coumarins 343 and D-1421 as relatively clean forward and return waves at 0.99 and $1.20 \mathrm{~V}$, respectively. Reduction of the dyes was irreversible. Although peak potentials were measured at -1.45 and $-1.40 \mathrm{~V}$ vs. SCE in reduction forward waves for coumarins 343 and D-1421, reduction return waves were not observed. In the system of D-126, oxidation was irreversible (1.04 V), and reduction was quasireversible $(-2.20 \mathrm{~V})$. The direct determination for the redox potential of excited state

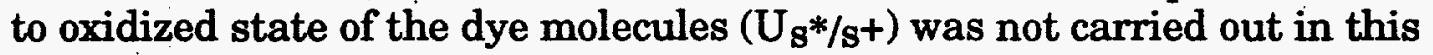
experiment. We assumed that the first reduction potentials $\left(\mathrm{U}_{\mathrm{s}} / \mathrm{s}\right)$ determined by the above electrochemical measurements correspond to $\mathrm{U}_{\mathrm{S}} * / \mathrm{s}+$ of the dyes under the present condition.

To assign the rapid excited state dye processes for the coumarin-sensitized $\mathrm{ZnO}$ dispersions observed in the femtosecond emission experiment, it is first necessary to know the values of the excited state lifetime in the absence of $\mathrm{ZnO}$ nanoclusters. The TCSPC emission lifetime data are given in Table I. While the approximately $4 \mathrm{~ns}$ lifetimes for the coumarins 343 and D-126 in methanol are unremarkable, the lifetime for the D-1421 dye is a factor of four shorter. This indicates that in the free dye some dynamical processes are contributing to the relevant excited state dynamics, leading to a more rapid non-radiative decay.

Table I. Fluorescence lifetimes of coumarins in methanol, measured by timecorrelated single photon counting (TCSPC). Excitation $406 \mathrm{~nm}$.

$\begin{array}{ccc}\text { coumarin } & \begin{array}{c}\text { Emission } \\ \text { wavelength } \\ \text { (nm) }\end{array} & \begin{array}{c}\text { Emission } \\ \text { lifetime } \\ \text { (ns) }\end{array} \\ 343 & 475 & 3.74 \\ \text { D-1421 } & 465 & 0.985 \\ \text { D-126 } & 450 & 4.00\end{array}$

The time-integrated absorption and emission spectra for the dye/ZnO dispersions are shown in Figure 4. For the coumarin dyes 343 and D-1421, there is clear evidence of strong surface interaction as $\mathrm{ZnO}$ is added to the dye solution (not shown). At the concentrations used for the femtosecond emission experiments, there is a noticeable blue-shift in the absorption spectrum for coumarins 343 (30 $\mathrm{nm}$ ) and $\mathrm{D}-1421(16 \mathrm{~nm})$ in $\mathrm{ZnO}$ dispersions. Only a very small shift of $<2 \mathrm{~nm}$ is observed in the D-126/ZnO dispersion relative to the methanol-dye solution. For the $\mathrm{C} 343 / \mathrm{ZnO}$ dispersion, emission quenching is clearly observed. Much less substantial quenching occurs for D-1421/ZnO dispersions. A factor of four less steady-state quenching would be expected because of the difference in excited state lifetimes between D-1421 and the other two coumarins, 343 and D-126. Though the absorption spectra of $\mathrm{D}-126$ and $\mathrm{D}-126 / \mathrm{ZnO}$ show a much weaker interaction, there is an approximate $50 \%$ decrease in peak emission intensity for the D-126/ZnO system relative to the free dye solution. Extrapolating the charge carrier injection 
rate from time-integrated emission studies is likely to be incorrect, because the interfacial electron-transfer is but one of several possible decay pathways for the excited state of the photosensitizing dye. If the rates of competing processes are substantial, then only a direct measure of the excited state dynamics in the time domain will suffice to determine the interfacial electron-transfer dynamics directly.

The femtosecond time-resolved emission data shown in Figures 5 and 6 reveal the true excited state dynamics of the dye adsorbed on the $\mathrm{ZnO}$ nanoclusters. The fs fluorescence upconversion spectrometer has a time window limited to $<1 \mathrm{~ns}$ because of the travel length of the scanning delay stage. Both long scans (Figure 5) and short scans (Figure 6) were measured for the photosensitized $\mathrm{ZnO}$ systems. The long scans were measured with a data point taken every $3.33 \mathrm{ps}$, while the short scans were measured with 13.34 fs per point.

In Figure 5 (top), a very rapid decay process in the excited-state of coumarin 343 adsorbed on $\mathrm{ZnO}$ is observed, with a bi-exponential fit giving a long lifetime of $>6 \mathrm{~ns}, 43 \%$ amplitude, with a short component of $3.65 \mathrm{ps}, 57 \%$ amplitude. The presence of a rapid component is unambiguous, but the fitted value of $3.65 \mathrm{ps}$ must be viewed cautiously, because of the $3.33 \mathrm{ps} /$ point data spacing. To characterize the rapid dynamics correctly, a scan with more densely spaced time points is needed, shown in Figure 6 (top). The results of the fit to this $6 \mathrm{ps}$ window are shown in Table II. A multi-exponential decay for $\mathrm{D}-1421$ on $\mathrm{ZnO}$ is observed on the long timescale plot in Figure 5. A best fit with no constrained parameters was obtained, and then refined with equally good statistics by forcing the longest decay component equal to the value of the excited state lifetime of the free dye in methanol. Again, the fit parameters are found in Table II. The data for D-126 and $\mathrm{ZnO}$ nanoclusters in methanol is shown in Figure 5 (bottom). The dominant feature of this transient is surprising: a long rise-time, not a rapid decay. Careful observation of the data reveals a convex, rather than concave curvature to the decay at times from 100-900 ps, indicating that the rise is actually bi-exponential: The long decay time of $1.36 \mathrm{~ns}$ is a factor of three shorter than the emission lifetime of the free dye. The absorption spectra and electrochemistry data, combined with the rising emission dynamics transient, show that the coumarin D-126 is not acting at all like the ideal photosensitizer illustrated in Figure 1 and described in the Introduction.

Table II. Excited state dynamics of coumains in $\mathrm{ZnO} /$ methanol dispersions, fit to a sum of up to three exponential decay components. A negative amplitude $A_{i}$ indicates an exponential rise rather than a decay. The superscript $f_{\text {indicates that }}$ this parameter was fixed during the fitting procedure to match the measured emission lifetime in methanol.

$\begin{array}{ccccccc}\text { Coumarin } & \mathrm{A}_{1} & \tau_{1}(\mathrm{ps}) & \mathrm{A}_{2} & \tau_{2}(\mathrm{ps}) & \mathrm{A}_{3} & \tau_{3}(\mathrm{ps}) \\ 343 & 0.1639 & 0.33 & 0.1494 & 3.47 & 0.6867 & 3740 \mathrm{f} \\ \mathrm{D}-1421 & 0.2576 & 19.6 & 0.5155 & 196.5 & 0.2269 & 985 \mathrm{f} \\ \mathrm{D}-126 & -2.852 & 13.1 & -3.076 & 489.2 & 1.000 & 1358.3\end{array}$


The ultrafast dynamics of coumarins 343 and D-1421 on $\mathrm{ZnO}$ are shown at high time resolution in Figure 6. In addition to the lifetime of about $3.5 \mathrm{ps,} \mathrm{a}$ substantially faster lifetime of $330 \mathrm{fs}$ is required to fit the data for coumarin 343 on $\mathrm{ZnO}$. No risetime could be fit to this data. This indicates that with our measured time resolution, if a dynamic process leading to a risetime were present, it must be faster than $25 \mathrm{fs}$. In contrast, the data for D-1421 on $\mathrm{ZnO}$ show the need for a $350 \mathrm{fs}$ risetime in the fit, and a $34.9 \mathrm{ps}$ decay (a value in between the 20 and $200 \mathrm{ps}$ time constants fit for D-1421/ZnO in Figure 5, constrained by the 3 ps time window of this data set). The risetime is a lag-time prior to interfacial electron-transfer for D1421 sensitized $\mathrm{ZnO}$. It is unlikely that this risetime results from vibrational relaxation for coumarin $\mathrm{D}-1421 / \mathrm{ZnO}$; coumarin chromophores of similar size have intramolecular vibrational relaxation occurring in $<50 \mathrm{fs}^{27}$ A possible explanation is that since we are observing the emission dynamics on the red side of the spectrum, the risetime could result from dynamical solvation leading to a timedependent fluorescence Stokes shift. The ultrafast solvation dynamics of a related molecule in methanol solution, coumarin 153 , have been studied in detail. ${ }^{27,28}$ The experimental time correlation function for the energy relaxation occurring as a result of fluctuations of the methanol solvent has four exponential time constants: $30 \mathrm{fs} ; 280 \mathrm{fs}, 3.2 \mathrm{ps}$, and $15.3 \mathrm{ps}$. The shortest time constant results from librational fluctuations of the hydrogen-bonded hydroxy group. The $280 \mathrm{fs}$ value is assigned to collision-induced fluctuations in the solvent. The longer two time constants of 3.2 and $15.3 \mathrm{ps}$ result from diffusive reorientation of the methanol molecules. All of these solvent fluctuation processes are expected to affect rapid electron-transfer reactions, though with a different weighting factor than would be observed for the free dye molecule.

We are confident that the very rapid excited-state dynamical processes observed in the coumarins adsorbed onto $\mathrm{ZnO}$ results from electron-transfer to the $\mathrm{ZnO}$ nanocluster. In a number of systems, other organic dye photosensitizers adsorbed on $\mathrm{ZnO}$ electrodes have produced substantial photocurrent. ${ }^{3-7}$ Coumarin 343 has been shown to be an excited-state electron donor when adsorbed on $\mathrm{TiO}_{2}$ by two methods. First, current proportional to light flux is obtained from a coumarin 343 sensitized $\mathrm{TiO}_{2}$ photoelectrochemical cell. Second, transient absorption measurements observe the radical-cation species of coumarin $343 .{ }^{33,34}$ However, we note that our assignment of the excited state decay processes for these coumarin photosensitized $\mathrm{ZnO}$ systems is based on inference from the prior work; we have not yet measured photocurrent or transient absorption from coumarin/ZnO systems.

The analysis of the time-resolved emission dynamics provides us with the interfacial electron-transfer rate constants. The effective rate constant for electron transfer is the inverse of the weighted average lifetime:

$$
\mathbf{k}_{\mathrm{ET}}=1 /\langle\tau\rangle ; \quad\langle\tau\rangle=\frac{\mathrm{a}_{1}}{\mathrm{a}_{1}+\mathrm{a}_{2}} \tau_{1}+\frac{\mathrm{a}_{2}}{\mathrm{a}_{1}+\mathrm{a}_{2}} \tau_{2}
$$

For $\mathrm{ZnO}$ dispersions photosensitized by coumarin 343 , we obtain $\mathrm{k}_{\mathrm{ET}}=5.5 \times 10^{11} \mathrm{~s}^{-1}$ from the 0.33 and $3.47 \mathrm{ps}$ components of the fast decay. The interfacial electrontransfer for $\mathrm{D}-1421$ sensitized $\mathrm{ZnO}$ is much slower. If we assume that both the 20 and $197 \mathrm{ps}$ decay components arise from interfacial electron-transfer, then $k_{E T}=7.3 \times 10^{9} \mathrm{~s}^{-1}$. A possible explanation for the substantially slower electron- 
transfer to $\mathrm{ZnO}$ from coumarin $\mathrm{D}-1421$ relative to 343 is that weaker interaction between $\mathrm{ZnO}$ surface and the dye molecule leads to the interfacial electron-transfer described as a non-adiabatic 'normal' Marcus regime photoreaction.

One factor in understanding the relatively slow interfacial electron-transfer in both these cases may be the effect of methanol on the $\mathrm{ZnO}$ nanocluster surface. Single crystal studies show a range of binding behavior for alcohols, but especially methoxide groups attached to the $\mathrm{Zn}^{2+}$ sites on the surfaces. ${ }^{21}$ Because of the $\mathrm{LiOH}$ used in the synthetic procedure, we may expect methoxide binding to be far more likely than methanol $\mathrm{H}$-bonding. For the case of coumarin 343, we have evidence that the dye is tightly bound from the value of $K_{a p p}=1910 M^{-1}$. However, the likelihood of surface binding methoxide on $\mathrm{ZnO}$ in methanol dispersion means that the electronic structure of particles may be substantially modified. In nanocrystalline systems, such a change of surface structure significantly modifies surface electronic structure as well as the energies of whole particle, i.e., band structure. The adsorption of negatively charged methoxide should cause conduction band edge shift to negative potential, leading to slower injection. As mentioned in the introduction, we find that the charge injection rate to photosensitized $\mathrm{TiO}_{2}$ is larger than the rate for injection into $\mathrm{ZnO}$, using the same photosensitizer. Redmond, et al. have estimated that the density of states for the conduction band of $\mathrm{TiO}_{2}$ has been estimated to be 113 times the density of states for $\mathrm{ZnO}{ }^{32}$ The theories of Marcus and Levich describing interfacial electron-transfer ${ }^{2}$ would then predict faster electron-transfer for photosensitized $\mathrm{TiO}_{2}$ versus $\mathrm{ZnO}$, as observed.

Rapid interfacial electron-transfer in photosensitized semiconductors has long been rationalized by a scheme such as described in Figure 1. 19,35 Timeresolved spectroscopy of the dye sensitizer excited states have been carried out for tin disulfide $\left(\mathrm{SnS}_{2}\right)$. Willig, et al. measured charge carrier injection from cresyl violet sensitized $\mathrm{SnS}_{2}$ with a dye excited state decay less than their $10 \mathrm{ps}$ instrument-limited response, and assigned this to interfacial electron transfer into the $\mathrm{SnS}_{2}$ conduction band. ${ }^{22}$ A similar explanation was given by Lanzafame, et al., who used oxazine dye as a photosensitizer for $\mathrm{SnS}_{2}$. Though the excited state decay they measured was limited by the $40 \mathrm{ps}$ instrument response, by careful calibration of the time versus intensity quenching in this experiment, they estimated that the interfacial electron transfer occurred in $40 \mathrm{fs}^{36}$

Very rapid adiabatic interfacial electron-transfer has recently been observed for nanocrystalline photosensitized $\mathrm{TiO}_{2}$ films or dispersions in at least three different laboratories. Tachibana, et al. studied the RuII dye used in the successful Grätzel-group photocell, adsorbed onto nanocrystalline $\mathrm{TiO}_{2}$ films. ${ }^{20}$ They observe rapid interfacial electron transfer with equally weighted time constants of 0.15 and $1.2 \mathrm{ps}$, leading to an effective rate constant of at least $\mathrm{kET}=1.5 \times 10^{12} \mathrm{~g}^{-1}$. These authors are careful to point out that the $150 \mathrm{fs}$ time constant is instrument limited, and that the true rate may be even faster. Rehm, et al. studied coumarin 343 photosensitized $\mathrm{TiO}_{2}$, dispersed in $95 \%$ water $/ 5 \%$ acetone solvent, and found an excited state decay of $<190 \mathrm{fs}$ (instrument limited), corresponding to an adiabatic rate constant of $\mathrm{kET}_{\mathrm{ET}}$ exceeding $5.3 \times 10^{12} \mathrm{~s}^{-1}$. ${ }^{17}$ We have studied the same three coumarins reported on here, adsorbed on $53 \AA$ diameter $\mathrm{TiO}_{2}$ nanoclusters in aqueous dispersions at $\mathrm{pH}$ 4. Our femtosecond emission results show dominant rapid decay time constants of $42 \mathrm{fs}$ (instrument limited) and $85 \mathrm{fs}$, for coumarins 
343 and D-1421, respectively. ${ }^{18}$ These time constants correspond to adiabatic

interfacial electron transfer rate constants of at least $2.4 \times 10^{13}$ and $1.2 \times 10^{13} \mathrm{~s}^{-1}$. 


\section{Summary and Future Directions}

We find that coumarins 343 and $\mathrm{D}-1421$ successfully photosensitize $\mathrm{ZnO}$ nanoclusters in methanolic dispersions, but that D-126 does not. The electrontransfer rates are rapid, but indicate an electronic coupling that is between nonadiabatic and adiabatic. The similarities between these dyes on $\mathrm{ZnO}$ and on $\mathrm{TiO}_{2}$ in methanol indicate that a non-alkanol solvent, especially aqueous dispersion, may well lead to the type of extremely rapid charge carrier injection dynamics found for photosensitized $\mathrm{TiO}_{2}$ in water. The $\mathrm{ZnO}$ nanoclusters used in this study were not stable in water. However, an alternative preparation by Bahnemann provides $50 \AA$ diameter wurtzite $\mathrm{ZnO}$ nanoclusters that are stable in aqueous dispersion. ${ }^{10}$ It will be of great interest to measure the photo-induced interfacial electron-transfer for photosensitizers such as coumarin 343 or $\mathrm{Ru}^{\mathrm{II}}$-polypyridyl dyes to learn whether extremely rapid, adiabatic charge carrier injection becomes possible with aqueous nanocrystalline $\mathrm{ZnO}$.

\section{Acknowledgments}

The research carried out at Brookhaven National Laboratory (E.W.C.) was funded under contract DE-AC02-76CH00016 with the U.S. Department of Energy and supported by its Division of Chemical Sciences, Office of Basic Energy Sciences. K.M and S.Y. wish to thank the Monbusho International Scientific Research Program: Joint Resarch for support. E.W.C. wishes to thank Prof. S. H. Courtney for a loan of the nonlinear least-squares fitting program used in analyzing the is fluorescence and TCSPC data, and Dr. M.-L. Horng and Prof. M. Maroncelli at Penn State for invaluable advice during the setup of the femtosecond fluorescence upconversion spectrometer.

\section{Literature Cited}

(1) Hagfeldt, A.; Grätzel, M., Chem. Rev. 1995, 95, 49-68.

(2) Willig, F. In Surface Electron Transfer Processes; R. J. D. Miller, G. L. McLendon, A. J. Nozik, W. Schmickler and F. Willig, Ed.; VCH: New York, NY, 1995; pp 167-309.

(3) Gerischer, H.; Tributsch, H., Ber. Bunsenges. Phys. Chem. 1968, 72, 437-445.

(4) Tributsch, H.; Gerischer, H., Ber. Bunsenges. Phys. Chem. 1968, 73, 251-260.

(5) Tsubomura, H.; Matsumura, M.; Nomura, Y.; Amamiya, T., Nature 1976, 261, 402-403.

(6) Matsumura, M.; Nomura, Y.; Tsubomura, H., Bull. Chem. Soc. Jpn. 1977,50, 2533-2537.

(7) Alonso, N.; Beley, V. M.; Chartier, P.; Ern, V., Revue Phys. Appl. 1981, 16, 5-

10. 
(8) Clark, W. D. K.; Sutin, N., J.A.C.S. 1977, 99, 4676-4682.

(9) Spanhel, L.; Anderson, M. A., J.A.C.S. 1991 113, 2826-2833.

(10) Bahnemann, D. W., Israel Journal of Chemistry 1993, 33, 115-136.

(11) Cavaleri, J. J.; Skinner, D. E.; Colombo, J., D. Phillip; Bowman, R. M., J. Chem. Phys. 1995, 103, 5378-5386.

(12) Dare-Edwards, M. P.; Goodenough, J. B.; Hamnett, A.; Seddon, K. R.; Wright, R. D., Journal of the Chemical Society: Faraday Discussions 1980, 70, 285-298.

(13) Péchy, P.; Rotzinger, F. P.; Nazeeruddin, M. K.; Kohle, O.; Zakeeruddin, S. M.; Humphry-Baker, R.; Grätzel, M., J. Chem. Soc., Chem. Commun. 1995, 65-66.

(14) Yan, S.; Hupp, J. T., J. Phys. Chem. 1996, 100, 6867-6870.

(15) Jones, G. I.; Griffin, S. F.; Choi, C.-y.; Bergmark, W. R., J. Org. Chem. 1984, $49,2705-2708$.

(16) Yoshihara; K.; Tominaga, K.; Nagasawa, Y., Bull. Chem. Soc. Jpn. 1995,68, 696-712.

(17) Rehm, J. M.; McLendon, G. L.; Nagasawa, Y.; Yoshihara, K.; Moser, J.; Grätzel, M., J. Phys. Chem. 1996, 100, 9577-9578.

(18) Murakoshi, K.; Yanagida, S.; Castner, E. W., Jr., to be submitted to JACS 1997,

(19) Nazeeruddin, M. K.; Kay, A.; Rodicio, I.; Humphry-Baker, R.; Müller, E.; Liska, P.; Vlachopoulos, N.; Grätzel, M., J.A.C.S. 1993, 115, 6382-6390.

(20) Tachibana, Y.; Moser, J. E.; Grätzel, M.; Klug, D. R.; Durrant, J. R., J. Phys. Chem. 1996, 100, 20056-20062.

(21) Heinrich, V. E.; Cox, P. A., The Surface Science of Metal Oxides; 1 ed.; Cambridge University Press: Cambridge, UK, 1994, p 278.

(22) Willig, F.; Eichberger, R.; Sundaresan, N. S.; Parkinson, B. A., J.A.C.S. 1990, $112,2702-2707$.

(23) Murakoshi, K.; Kano, G.; Wada, Y.; Yanagida, S.; Miyazaki, H.; Matsumoto, M.; Murasawa, S., Journal of Electroanalytical Chemistry 1995,396, 27-34.

(24) Petrie, W. T.; Vohs, J. M., Surface Science 1991 245, 315-323.

(25) Capel, M., http://crim12b.nsls.bnl.gov/x12b.htm:

WWW reference for NSLS Beamline X12B, Upton, NY, for 1997.

(26) Castner, E. W., Jr., 1997, in preparation, 
(27) Horng, M. L.; Gardecki, J. A.; Papazyan, A.; Maroncelli, M., J. Phys. Chem. 1995, 99, 17311-17337.

(28) Rosenthal, S. J.; Jiminez, R.; Fleming, G. R.; Kumar, P. V.; Maroncelli, M., Journal of Molecular Liquids 1994, 60, 25-56.

(29) Chapman, C. F.; Fee, R. S.; Maroncelli, M., J. Phys. Chem. 1990, 94, 49294935.

(30) Nosaka, Y., J. Phys. Chem. 1991, 95, 5054-5058.

(31) Glatter, O.; Kratky, O., Small Angle X-ray Scattering; Academic Press: New York, NY, 1982, pp 515.

(32) Redmond, G.; O'Keefe, A.; Burgess, C.; MacHale, C.; Fitzmaurice, D., J. Phys. Chem. 1993, 97, 11081-11086.

(33) Moser, J. E.; Grätzel, M., Chem. Phys. 1993, 176, 493-500.

(34) Castner, E. W., Jr.; Murakoshi, K., unpublished results.

(35) O'Regan, B.; Grätzel, M., Nature 1991 353, 737-739.

(36) Lanzafame, J. M.; Miller, R. J. D.; Muenter, A. A.; Parkinson, B. A., J. Phys. Chem. 1992, 96, 2820-2826. 


\section{Figure Captions}

Figure 1. Diagram of the spherical $\mathrm{ZnO}$ semiconductor nanocluster with an adsorbed coumarin dye photosensitizer. The semiconductor energy levels are shown descriptively at the left. On the right, the relevant energy levels are shown for the neutral dye molecule. The optical transition between the ground electronic state and vibrationally populated excited electronic state is represented by the vertical arrow labeled $\mathrm{hv}\left(\mathrm{S}_{1, \mathrm{v}} \leftarrow \mathrm{S}_{0,0}\right)$. The downward vertical arrow represents both intramolecular vibrational relaxation and dye-solvent dynamical interactions. The dashed arrow in the direction of the semiconductor conduction band represent the charge carrier (electron) injection into the n-type semiconductor.

Figure 2. Models for binding of coumarin oxygens coordinated to $\mathrm{Zn}^{2+}$ cation sites on $\mathrm{ZnO}$ surface. Other models are feasible in addition to the four presented here.

Figure 3. Small-angle x-ray scattering data for $\mathrm{ZnO}$ nanoclusters dispersed in methanol (not photosensitized). Data were obtained at beamline X12B at the National Synchrotron Light Source. Top: raw data of scattered intensity versus wavevector q. Bottom: Guinier plot of Ln intensity versus $\mathbf{q}^{2}$.

Figure 4. Absorption and emission spectra are shown for (top to bottom) coumarins 343, D-1421, and D-126 in methanol and in $\mathrm{ZnO} /$ methanol dispersions. The solid lines are for the spectra of coumarin/methanol solutions, while the dashed lines are for the coumarins/ZnO/methanol dispersions. Optical pathlength for absorption measurements of C343 and D-1421 were $10 \mathrm{~mm}$; for D-126, 2mm. The uncorrected emission spectra were measured in $1.0 \mathrm{~mm}$ path cells, on the instrument built at Brookhaven.

Figure 5. Longer-time emission dynamics measured by femtosecond fluorescence upconversion spectroscopy. Dots are fluorescence upconversion data; fit is a sum of two or three exponentials, and residuals for fit are shown above the plot of data and fit.

Top: $[\mathrm{C} 343]=1.7 \times 10^{-4} \mathrm{M},[\mathrm{ZnO}]=10^{-2} \mathrm{M}$ methanol dispersion. Excitation wavelength $393 \mathrm{~nm}$; gated emission wavelength $480 \mathrm{~nm}$.

Middle: $[\mathrm{D}-1421]=9 \times 10^{-5} \mathrm{M} ;[\mathrm{ZnO}]=10^{-2} \mathrm{M}$ methanol dispersion. Excitation wavelength $393 \mathrm{~nm}$; gated emission wavelength $480 \mathrm{~nm}$. Bottom: [D-126] $=10^{-4} \mathrm{M} ;[\mathrm{ZnO}]=10^{-2} \mathrm{M}$ methanol dispersion. Excitation wavelength $398 \mathrm{~nm}$; gated emission wavelength $490 \mathrm{~nm}$.

Figure 6. Short-time femtosecond fluorescence upconversion data. Dots are fluorescence upconversion data; third-harmonic cross-correlation (instrument response) is symmetric about zero time delay; fit is a sum of three exponentials, and residuals for fit are shown above the plot of data and fit. Excitation wavelength is $393 \mathrm{~nm}$ gated emission wavelength is $480 \mathrm{~nm}$.

Top: $[\mathrm{C} 343]=1.7 \times 10^{-4} \mathrm{M},[\mathrm{ZnO}]=10^{-2} \mathrm{M}$ methanol dispersion.

Bottom: $[\mathrm{D}-1421]=9 \times 10^{-5} \mathrm{M} ;[\mathrm{ZnO}]=10^{-2} \mathrm{M}$ methanol dispersion. 


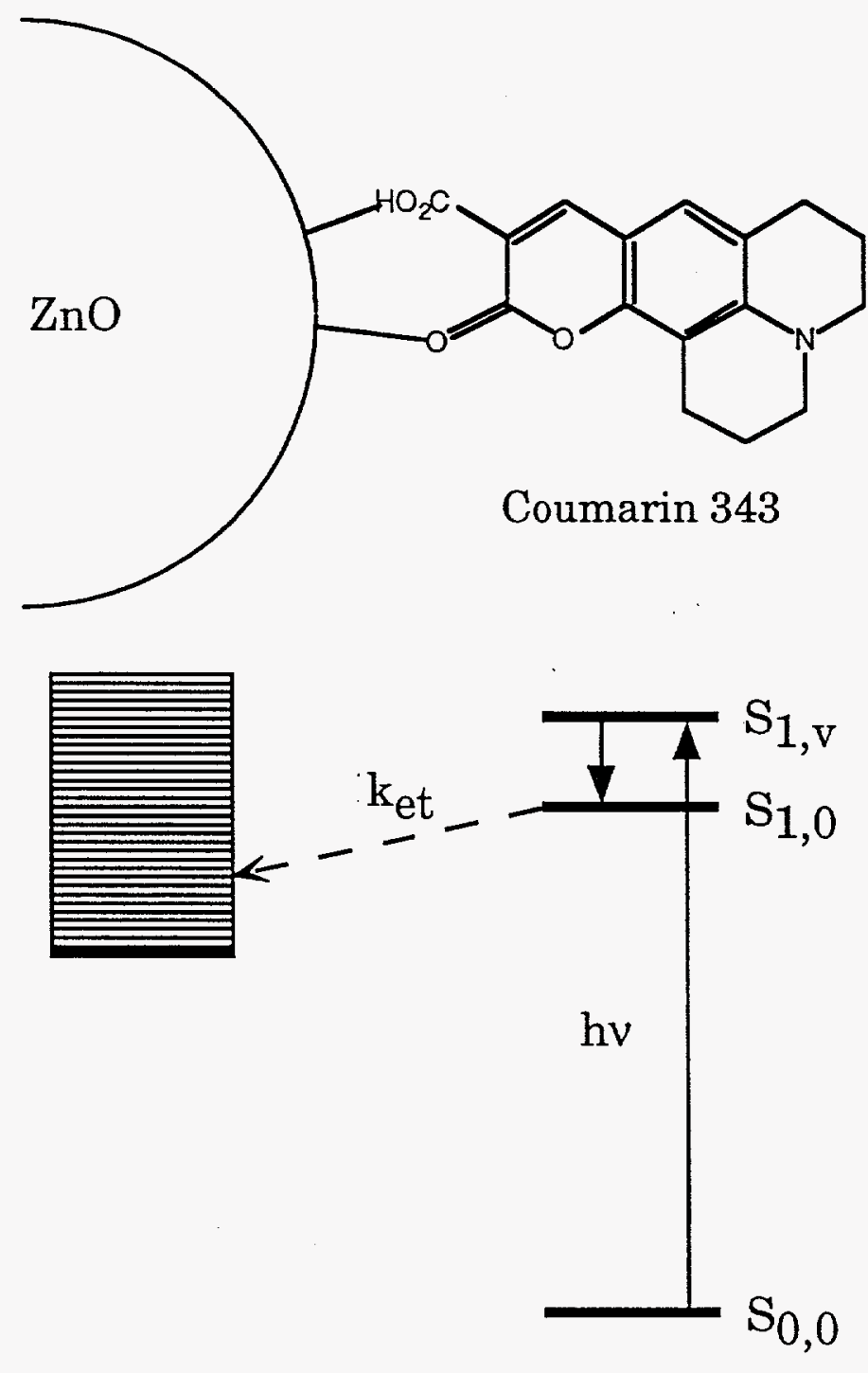

valence band

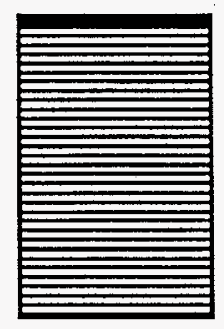

Figure 1. Murakoshi, Yanagida, Capel, Castner 


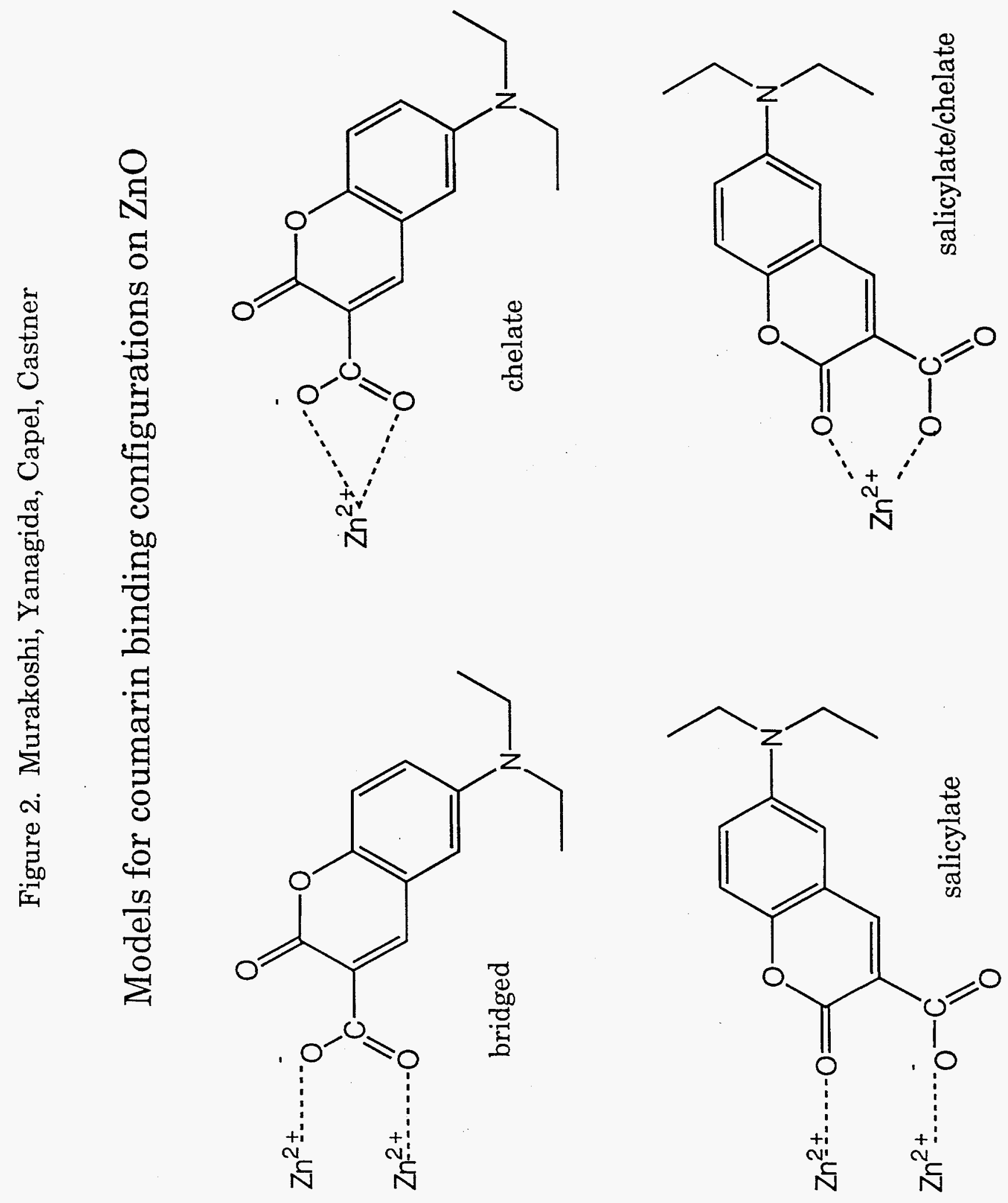


Figure 3. Murakoshi, Yanagida, Capel, Castner
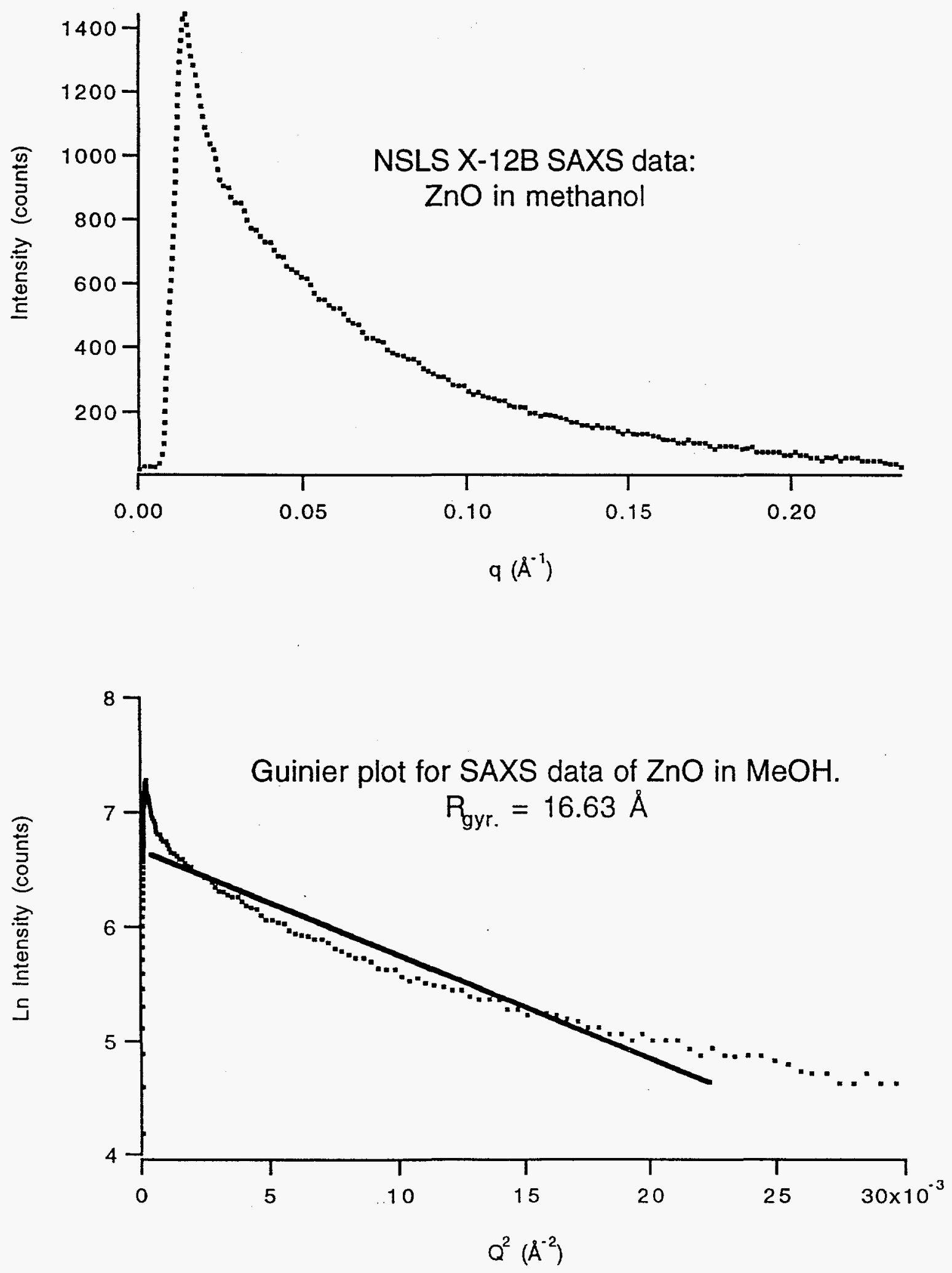
Figure 4. Murakoshi, Yanagida, Capel, Castner

\section{Absorption}
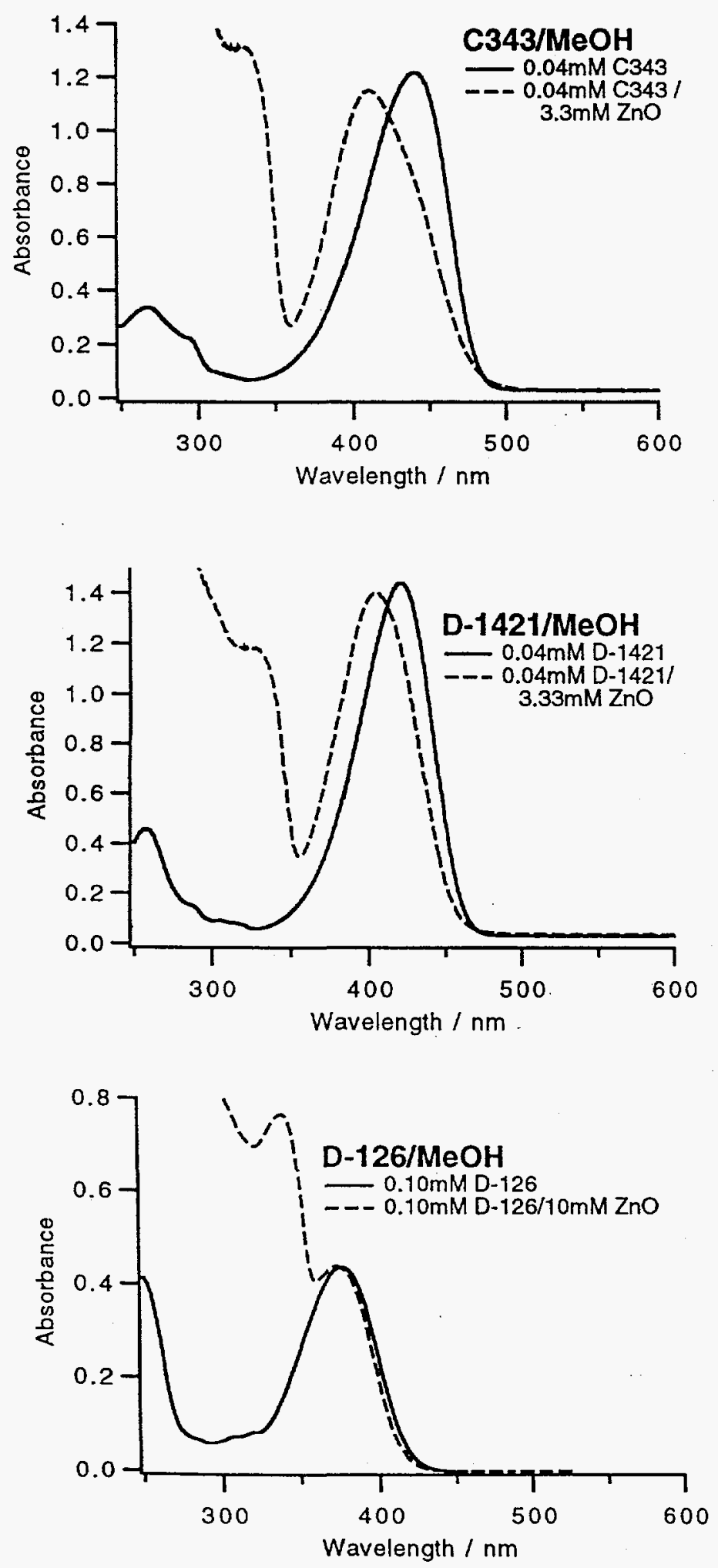

Emission
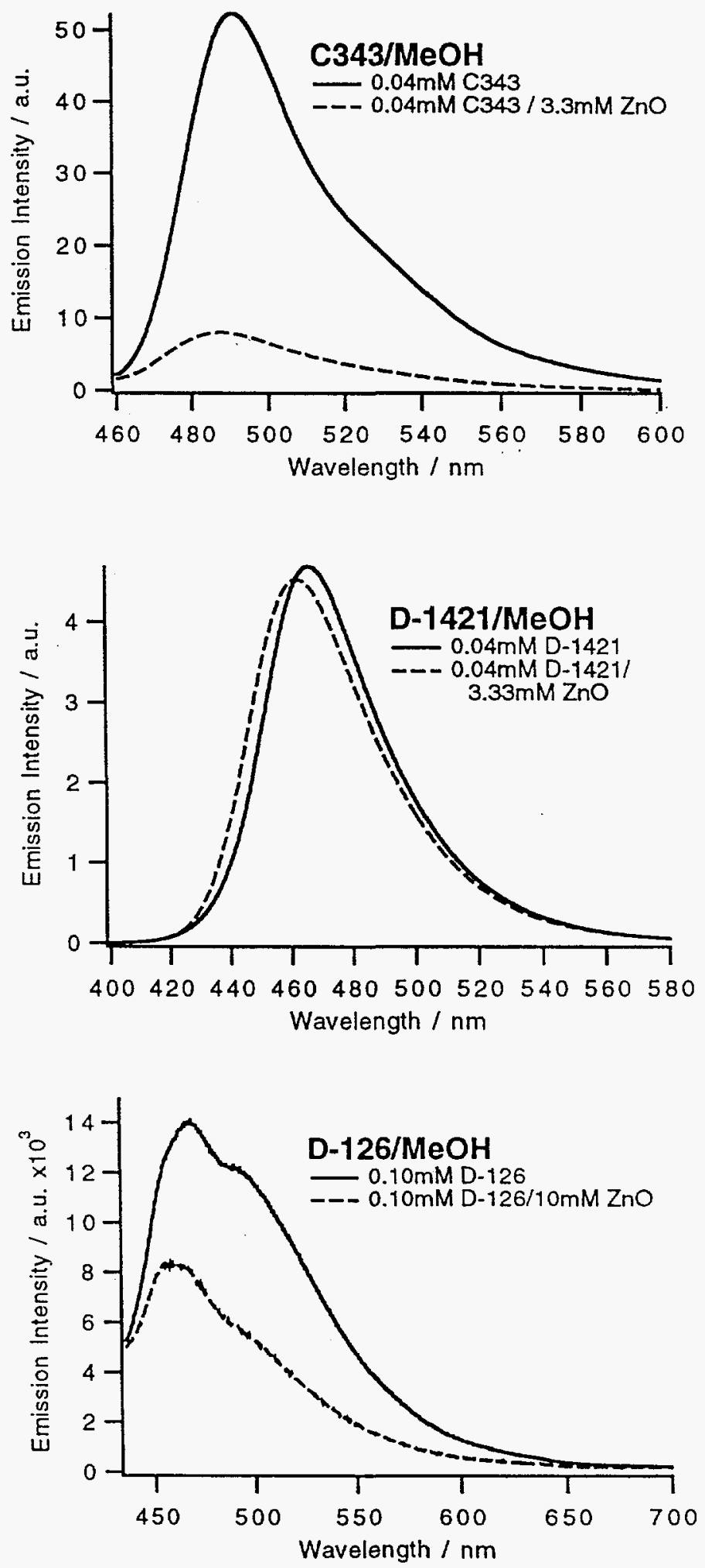

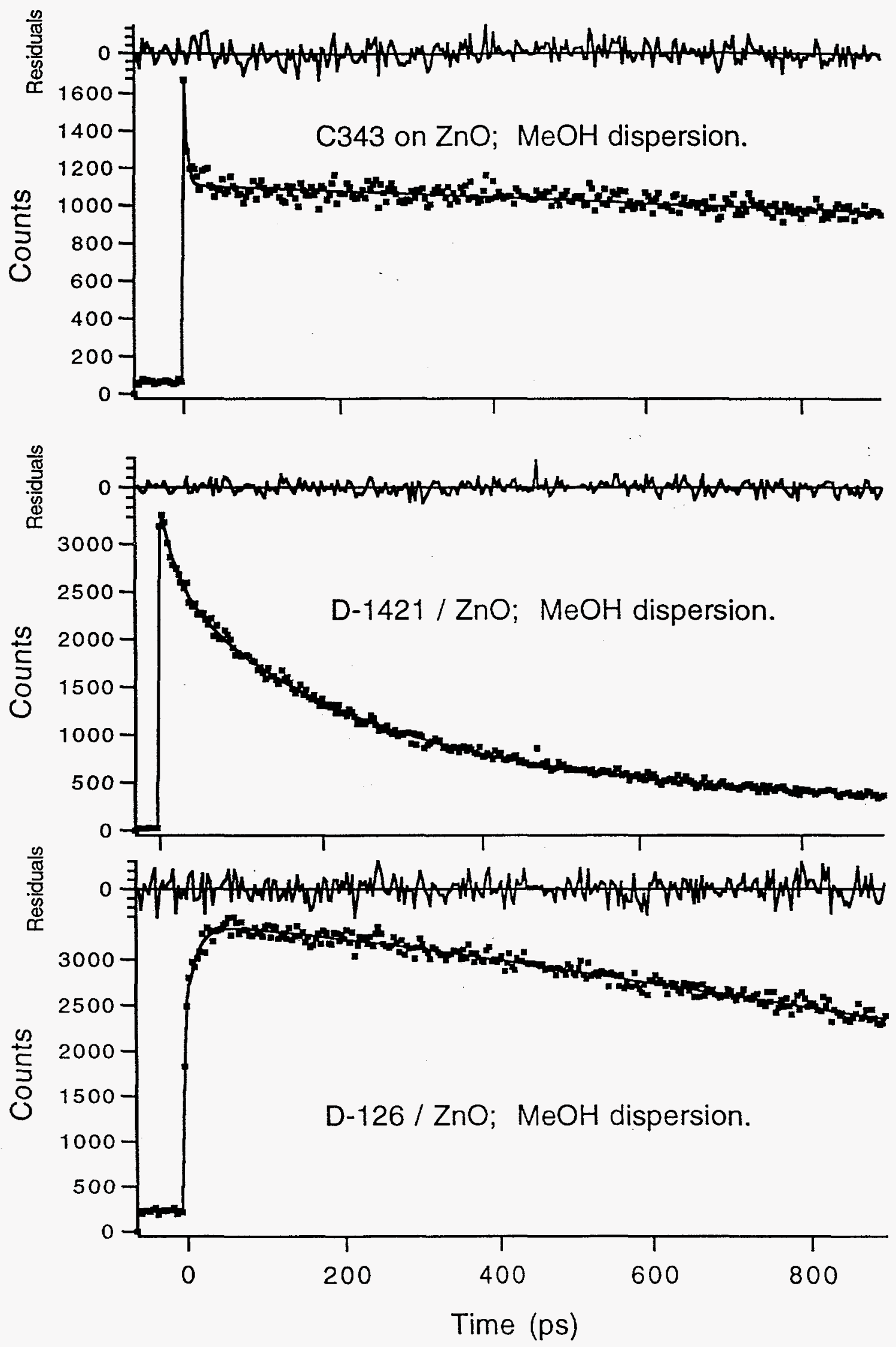

Time (ps) 

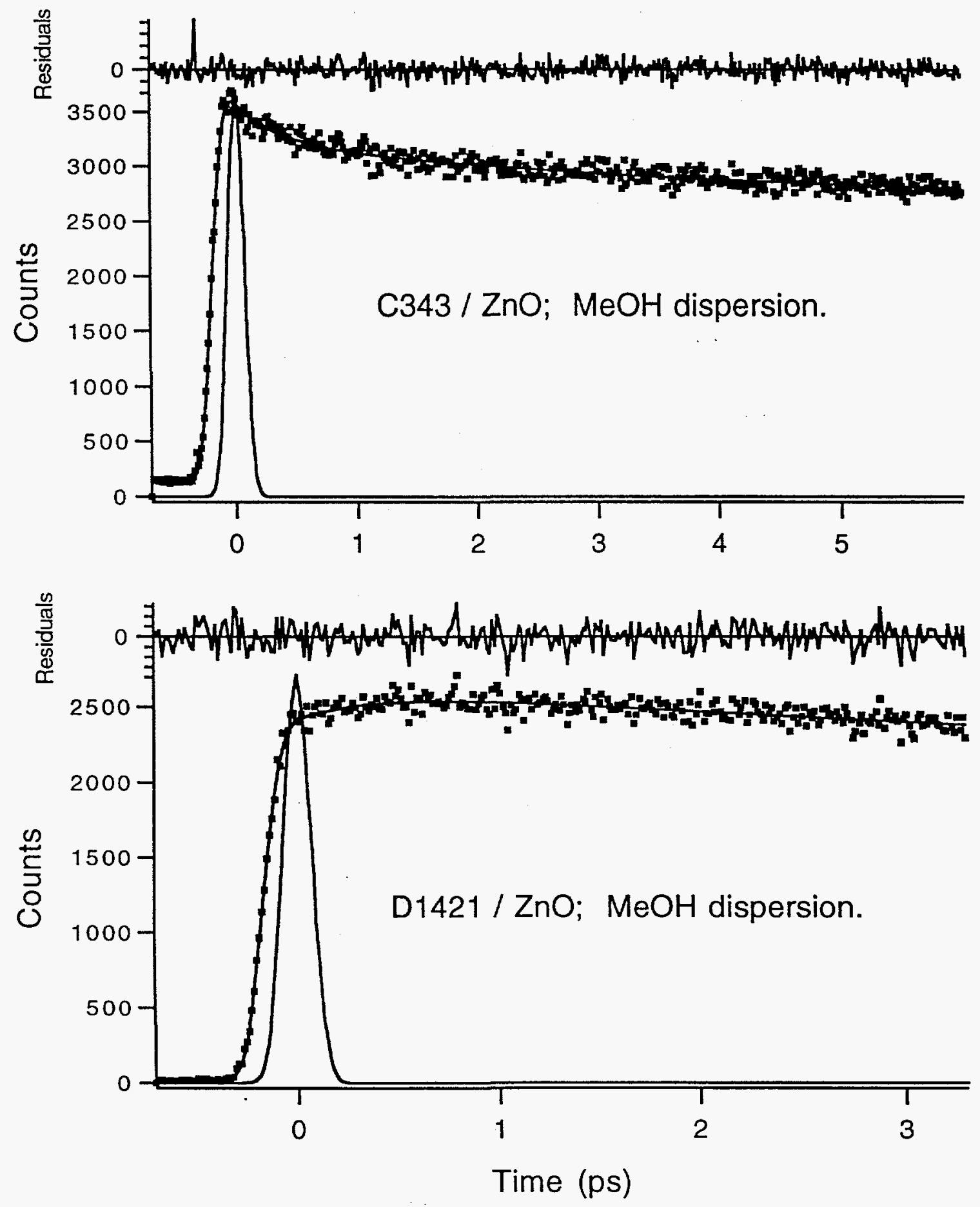

Figure 6. Murakoshi, Yanagida, Capel, Castner 